\title{
Investigating the status of Cinnamomum chago (Lauraceae), a plant species with an extremely small population endemic to Yunnan, China
}

\author{
Xue Zhang, Xiong-Li Zhou, Yuan-Huan Liu, Jin-Qiu Mo, Li-Qin Zhang \\ YuE-HuA WANG and SHI-KANG SHEN
}

\begin{abstract}
Cinnamomum chago is a woody species of the family Lauraceae endemic to Yunnan province, China, previously known from only one location, and categorized as a Plant Species with Extremely Small Population. We surveyed to determine the distribution and population size of C. chago, characterize its habitat, identify any threats, assess its conservation status, and provide guidelines for its management and conservation. During 2014-2017 we found only 64 mature C. chago, in five locations. These small, fragmented populations occur along Lancang River in Dali Prefecture at altitudes of 2,200-2,400 m. The species' extent of occurrence is c. $923 \mathrm{~km}^{2}$, with an area of occupancy of c. $60 \mathrm{~km}^{2}$. The habitat of the species has been degraded by expansion of pastoral activities and deforestation. We recommend categorization of $C$. chago as Endangered on the IUCN Red List, prevention of the collection of seeds and wood of the species, protection and monitoring, and ex situ propagation for future reintroductions.
\end{abstract}

Keywords China, Cinnamomum chago, conservation status, conservation strategy, endemic plant, extremely small population, habitat

hina is a high priority for biodiversity conservation, with $>30,000$ vascular plant species, of which c. 10,000 are endemics (Yang et al., 2005; Volis, 2016). In Yunnan province 1,010 stenochoric endemic seed plants have been recorded (Wu et al., 2011; Liu \& Peng, 2016). Species of the family Lauraceae have significant ecological and economic value (Ravindran et al., 2003; Huang et al., 2016; Zhang et al., 2018), with a total of 445 species (316 endemic) recorded in China, of which 109 are categorized as Endangered on the China Species Red List (Wang \& Xie, 2004; Yang \& Liu, 2015). The Lauraceae species Cinnamomum chago was first found in La-Guo village, Yunnan province, in 1988 (Sun \& Zhao, 1991), where it is a resource for timber and edible nuts (Plate 1). Its morphological features (opposite leaves,

Shi-Kang Shen (Corresponding author), Yue-Hua Wang (Corresponding author), Xue Zhang, Xiong-Li Zhou, Yuan-Huan Liu, Jin-Qiu Mo and Li-Qin Zhang School of Life Sciences, Yunnan University, Kunming No. 2 Green Lake North Road, Kunming 650091, Yunnan, China

E-mailssk168@ynu.edu.cn,wangyh58212@126.com

Received 11 August 2018. Revision requested 24 September 2018.

Accepted 3 December 2018. First published online 10 September 2019. pinnate leaf veins, naked bud and no glandular fossa) and phylogenetic analysis indicate that it is a key species in the phylogeny and evolution of Cinnamomun (Plate 2; Dong et al., 2016; Huang et al., 2016).

Lack of information on the distribution and status of a threatened endemic species can impede its conservation (Fenu et al, 2011; Wang et al., 2016; Laguardia et al., 2017). Previously, C. chago was known only from La-Guo village, at c. 2,300 m altitude (Sun \& Zhao, 1991). It is listed as one of the 321 Plant Species with Extremely Small Populations in south-west China that require comprehensive surveys and germplasm conservation (Yang \& Sun, 2017). As it had been suggested that $C$. chago could occur in other areas of Yunnan (Dong et al., 2016), we surveyed to characterize its distribution and habitat, identify any threats, assess its conservation status using the Red List categories and criteria (IUCN, 2012, 2017; Hoffman et al., 2008; Fenu et al., 2011), and provide guidelines for its management and conservation.

We firstly noted the characteristics of the specimens of C. chago deposited in the herbarium of Yunnan University, and verified the historical collection site in La-Guo village. We compiled information on $C$. chago from the literature and from experts, to identify sites where the species could potentially occur. At each potential site we showed photographs of the herbarium specimens and described the species' characteristics to local villagers and foresters. We received infomation regarding eight potential sites in Dali Prefecture, which we surveyed during the flowering (April-May) and fruiting seasons (September-October) of 2014-2017, noting the locations of any C. chago with a GPS, and the number of mature individuals, altitude and habitat type. The extent of occurrence and area of occupancy (IUCN, 2012, 2017), the latter using a $4 \mathrm{~km}^{2}$ grid, were determined with ArcGIS 10.3 (Esri, Redlands, USA).

We found 64 mature $C$. chago in five locations, in 120 days of surveys (Table 1). All populations, except that at La-Guo, are new discoveries (Fig. 1). The five populations occur in the mountains along Lancang River in Dali Prefecture, at altitudes of $2,200-2,400 \mathrm{~m}$. The total extent of occurrence is $923.23 \mathrm{~km}^{2}$ and the area of occupancy is $60.19 \mathrm{~km}^{2}$ (Table 1 ). The greatest distance between populations is $82.05 \mathrm{~km}$, between Da-Shi-Ba and Xin-Cun, and the shortest distance $\left(<_{1} \mathrm{~km}\right)$ is between Shun-Bi-Xiang and Xin-Cun (Fig. 1).

Habitat quality is important for the long-term persistence and survival of threatened plant species (Shen et al., 

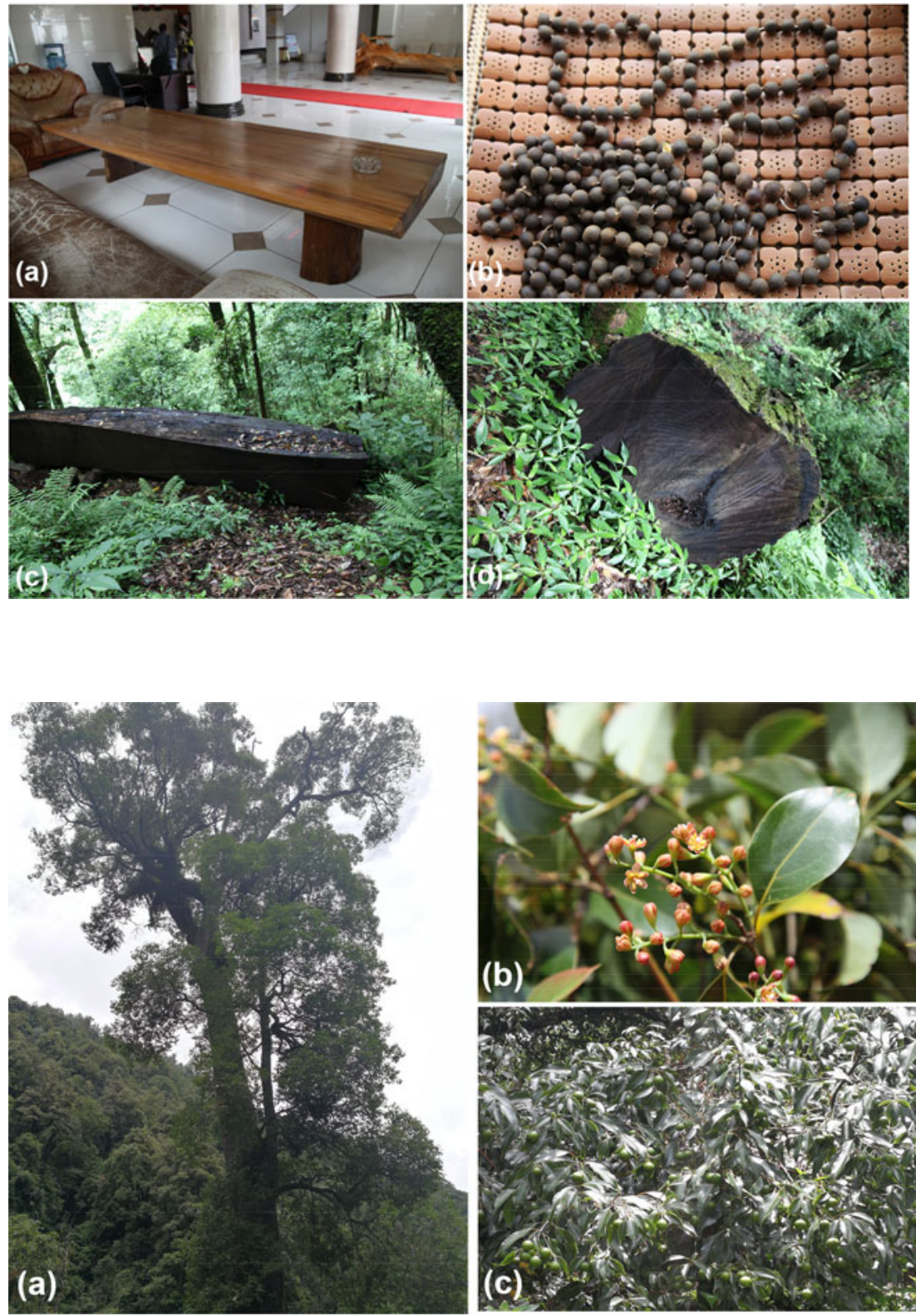

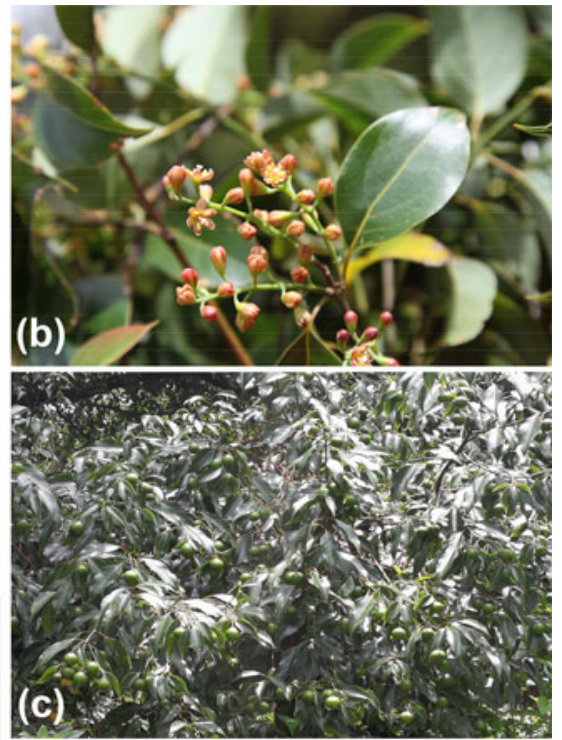

PLATE 1 Furniture made from the wood of C. chago (a), seeds traded in an agricultural market (b), and felled individuals (c \& d).
Plate 2 Cinnamomum chago (a), and its flowers (b) and fruits (c).

TABLE 1 Locations in which we confirmed the occurrence of Cinnamomum chago in Yunnan province, China, with geographical coordinates, altitude, number of mature individuals, area of occupancy and habitat type.

\begin{tabular}{llllll}
\hline Locations & $\begin{array}{l}\text { Geographical } \\
\text { coordinates }\end{array}$ & Altitude $(\mathrm{m})$ & $\begin{array}{l}\text { Mature } \\
\text { individuals }\end{array}$ & $\begin{array}{l}\text { Area of } \\
\text { occupancy }\left(\mathrm{km}^{2}\right)\end{array}$ & Habitat type \\
\hline La-Guo & $\begin{array}{l}99^{\circ} 55^{\prime} 9.20^{\prime \prime} \mathrm{E} \\
25^{\circ} 33^{\prime} 8.90^{\prime \prime} \mathrm{N} \\
99^{\circ} 56^{\prime} 33.40^{\prime \prime} \mathrm{E}\end{array}$ & 2,310 & 12 & 3.22 & Forest plantation \\
Xin-Cun & $\begin{array}{l}25^{\circ} 34^{\prime} 8.23^{\prime \prime} \mathrm{N} \\
99^{\circ} 56^{\prime} 28.35^{\prime \prime} \mathrm{E}\end{array}$ & 2,249 & 12 & 1.96 & Forest plantation \\
Shun-Bi-Xiang & $\begin{array}{l}25^{\circ} 34^{\prime} 13.27^{\prime \prime} \mathrm{N} \\
99^{\circ} 10^{\prime} 24.24^{\prime \prime} \mathrm{E}\end{array}$ & 2,317 & 14 & 0.41 & Forest plantation \\
Da-Shi-Ba & $\begin{array}{l}25^{\circ} 45^{\prime} 49.70^{\prime \prime} \mathrm{N} \\
99^{\circ} 16^{\prime} 35.03^{\prime \prime} \mathrm{E}\end{array}$ & 2,357 & 14 & 27.69 & Secondary evergreen broadleaved forest \\
Nan-Mu-Ping & $25^{\circ} 33^{\prime} 46.79^{\prime \prime} \mathrm{N}$ & & 12 & 26.91 & Secondary evergreen broadleaved forest \\
Total & & 64 & 60.19 & \\
\hline
\end{tabular}




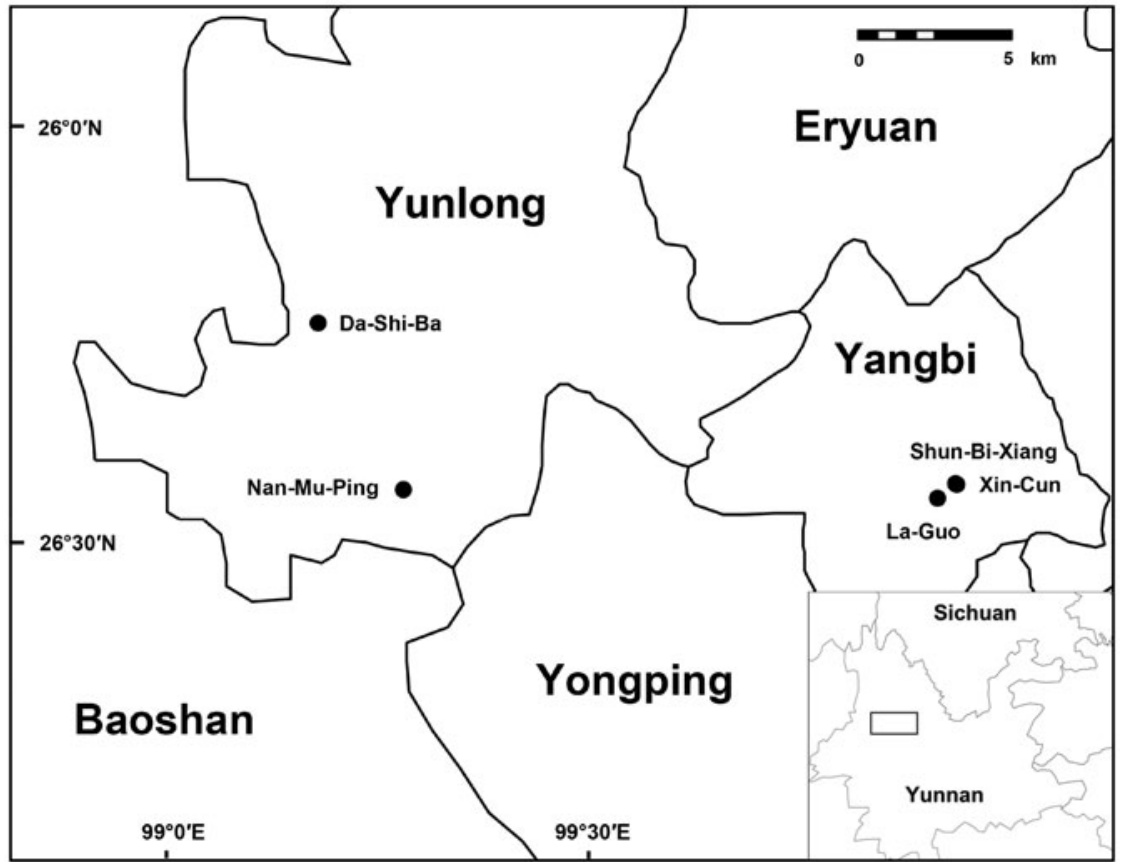

FIG. 1 The locations in which Cinnamomum chago was located in Yunnan province (La-Guo, where the species was first found, and four additional locations).
2009). The habitat of $C$. chago is of two types: secondary evergreen broadleaved forest and Juglans regia plantations. The populations in plantations (Table 1) are potentially exposed to high-frequency anthropogenic disturbance. None of the five populations lie within a protected area.

Expansion of pastoral activities and deforestation, and commercial utilization of the seeds and wood of C. chago, were detected in all five locations. In Nan-Mu-Ping $C$. chago had been felled to make furniture and other items. In all locations mature seeds of $C$. chago were collected by villagers and sold after processing. We found mature seeds gnawed by rodents, especially in Shun-Bi-Xiang, Xin-Cun and La-Guo, which are near villages. Our preliminary germination test indicated that the seeds of $C$. chago have deep dormancy, and our field observations indicate that healthy mature seeds begin to germinate under natural conditions in 1-2 years and that the germination rate is $<0.1 \%$. We hypothesize that overexploitation is one of the most significant threats to C. chago, as a result of which, combined with slow germination, regeneration is probably poor. We did not observe any seedlings or saplings of $C$. chago.

In summary, we found $<100$ mature $C$. chago, and its habitat has been degraded by human disturbance, confirming this is a species with an extremely small population (Sun, 2013). Cinnamomum chago was not included in the Threatened Species List of China's Higher Plants (Qin et al, 2017). We recommend categorization as Endangered based on IUCN Red List criteria (IUCN, 2012) 2ab(i,ii,iii, v), and make three additional recommendations. Firstly, the local forestry department needs to prevent the collection of the seeds and wood of C. chago. Secondly, as all located individuals occur outside protected areas, each population requires protection and monitoring (this strategy is already being implemented for other species with extremely small populations that do not lie in National Nature Reserves; Wang et al., 2016, 2017). Thirdly, as reintroduction has been successfully employed for other plant species with extremely small populations (Wade et al., 2016), such as Euryodendron excelsum (Shen et al., 2013), Magnolia sinica (Wang et al., 2016) and Primulina tabacum (Ren et al., 2010), seedlings should be propagated ex situ for this purpose.

Acknowledgements This study was funded by the Surveys and Germplasm Conservation of Plant Species with Extremely Small Populations project in south-west China (2017FY100100) under the Science \& Technology Basic Resources Investigation Programme, the National Key Research and Development Project (2017YFC0505204), the National Natural Science Foundation (31560224 and 31560224), the Young Academic and Technical Leader Raising Foundation of Yunnan Province (2018HB035), and the academic award for new doctoral candidates in Yunnan province (C6155501). We thank the administration of the local forestry department and Xu Peng of Xincun village for help with the survey.

Author contributions Secured funding, study design: S-KS, Y-HW; fieldwork and data analysis: all authors; writing and revision: XZ, S-KS.

\section{Conflicts of interest None.}

Ethical standards This research abided by the Oryx guidelines on ethical standards.

\section{References}

Dong, W., Zhang, X., YAng, Y.G., WAng, Y.H. \& Shen, S.K. (2016) Biological characteristics and conservation genetics of the narrowly 
distributed rare plant Cinnamomum chago (Lauraceae). Plant Diversity, 38, 247-252.

Fenu, G., Mattana, E. \& Bacchetta, G. (2011) Distribution, status and conservation of a Critically Endangered, extremely narrow endemic: Lamyropsis microcephala (Asteraceae) in Sardinia. Oryx, 45, 180-186.

Hoffman, M., Brooks, T.M., Dafonseca, G.A.B., Gascon, C., Hawkins, A.F.A., James, R.E. et al. (2008) Conservation planning and the IUCN Red List. Endangered Species Research, 6, 113-125.

HuAnG, J.F., Li, L., VAN DER WerfF, H., Li, H.W., Rohwer, J.G., Crayn, D.M. et al. (2016) Origins and evolution of cinnamon and camphor: a phylogenetic and historical biogeographical analysis of the Cinnamomum group (Lauraceae). Molecular Phylogenetics and Evolution, 96, 33-44.

IUCN (2012) IUCN Red List Categories and Criteria, Version 3.1. 2nd edition. IUCN, Gland, Switzerland, and Cambridge, UK.

IUCN (2017) Guidelines for Using the IUCN Red List Categories and Criteria, Version 13. IUCN Standards and Petitions Subcommittee, Gland, Switzerland, and Cambridge, UK.

Laguardia, A., Kamlera, J., Lia, S., Zhanga, C., Zhoua, Z. \& SHIA, K. (2017) The current distribution and status of leopards Panthera pardus in China. Oryx, 51, 160-160.

LIU, Z. \& PENG, H. (2016) Notes on the key role of stenochoric endemic plants in the floristic regionalization of Yunnan. Plant Diversity, 38, 289-294.

Qin, H.L., YANG, Y., Dong, Q.Y., He, Q., Jia, Y., ZhaO, L. et al. (2017) Threatened species list of China's higher plants. Biodiversity Sciences, 25, 696-744.

Ravindran, P.N., Nirmal-Babu, K. \& Shylaja, M. (2003) Cinnamon and Cassia: The Genus Cinnamomum. CRC Press, Boca Raton, USA.

Ren, H., Ma, G., Zhang, Q., Guo, Q., Wang, J. \& Wang, Z. (2010) Moss is a key nurse plant for reintroduction of the Endangered herb, Primulina tabacum Hance. Plant Ecology, 209, 313-320.

Shen, S.K., Wang, Y.H., WANG, B.Y., Ma, H.Y., Shen, G.Z. \& HaN, Z.W. (2009) Distribution, stand characteristics and habitat of a Critically Endangered plant Euryodendron excelsum H. T. Chang
(Theaceae): implications for conservation. Plant Species Biology, 24, $133-138$

Shen, S.K., WANG, Y.H., ZhanG, A.L., Wu, F.Q. \& JiAng, L.J. (2013) Conservation and reintroduction of a Critically Endangered plant Euryodendron excelsum. Oryx, 47, 17.

Sun, B.X. \& Zhaо, H.L. (1991) A new species of Cinnamomum from Yunnan, Kunming. Journal of Yunnan University, 13, 93-94.

Sun, W.B. (2013) Conserving Plant Species with Extremely Small Populations (PSESP) in Yunnan: a Practice and Exploration. Yunnan Science and Technology Press, Kunming, China. [in Chinese]

Volis, S. (2016) How to conserve threatened Chinese plant species with extremely small populations? Plant Diversity, 38, 45-52.

Wade, E.M., Nadarajan, J., Yang, X., Ballesteros, D., Sun, W. \& Pritchard, H.W. (2016) Plant species with extremely small populations (PSESP) in China: a seed and spore biology perspective. Plant Diversity, 38, 209-220.

WAnG, B., MA, Y., Chen, G., Li, C., DaO, Z. \& Sun, W. (2016) Rescuing Magnolia sinica (Magnoliaceae), a Critically Endangered species endemic to Yunnan, China. Oryx, 50, 446-449.

WANG, C., ZhanG, J., Wan, J., QU, H., Mu, X. \& ZhanG, Z. (2017) The spatial distribution of threats to plant species with extremely small populations. Frontiers of Earth Science, 11, 127-136.

W AnG, S. \& XIE, Y. (2004) China Species Red List. Higher Education Press, Beijing, China.

Wu, Z.Y., Sun, H., Zhou, Z.K., Li, D.Z. \& PenG, H. (2011) Floristics of Seed Plants From China. Science Press, Beijing, China.

YANG, J. \& SUN, W.B. (2017) A new programme for conservation of plant species with extremely small populations in southwest China. Oryx, 51, 396-397.

YANG, Q.E., ZhU, G.H., Hong, D.Y., WU, Z.Y. \& Raven, P.H. (2005) World's largest flora completed. Science, 309, 2163.

YANG, Y. \& LiU, B. (2015) Species catalogue of Lauraceae in China: problems and perspectives. Biodiversity Science, 23, 232-236.

Zhang, X, Zhang, Y., Wang, Y.H. \& Shen, S.K. (2018) Transcriptome analysis of Cinnamomum chago: a revelation of candidate genes for abiotic stress response and terpenoid and fatty acid biosyntheses. Frontiers in Genetics, 9, 505. 